\title{
CUMPLIMIENTO E INCUMPLIMIENTO Y RESPONSABILIDAD DEL DEUDOR EN EL CÓdIGO CIVIL. A PROPÓSITO DE LA SENTENCIA DE LA CORTE SUPREMA DE 7 DE SEPTIEMBRE DE 2010*
}

\author{
ÁlVARO VidAL OLIVARES** \\ MARÍA GraCIELA BRANTT ZUMARÁN***
}

RESUMEN: El objetivo de este artículo es analizar la sentencia de la Corte Suprema de 7 de septiembre de 2010, rol 1089 - 2009, a propósito del incumplimiento de la obligación de cuidado que recae sobre el establecimiento educacional respecto de sus estudiantes en virtud del contrato de educación.

PALABRAS CLAVE: Contrato de educación - incumplimiento - atribución de responsabilidad

\section{COMPLIANCE, BREACH AND LIABILITY OF THE DEBTOR IN THE CIVIL CODE. REgARDING THE SENTENCE BY THE SUPREME COURT ON SPETEMBER 7TH, 2010}

ABSTRACT: The objective of this article is to analyze the sentence by the Supreme Court on September 7th, 2010, role 1089-2009, regarding breach of contract in the obligation to provide care that falls on educational institutions about their students by virtue of the educational contract.

KEY WORDS: Education contract - breach - liability obligation

\footnotetext{
* Este artículo forma parte del proyecto Fondecyt Regular no 1100284 "Por una reforma a las reglas de incumplimiento contractual en el Código civil", y del proyecto Fondecyt Iniciación no 11100060 "La diligencia contractual como criterio de atribución de responsabilidad por incumplimiento en el derecho civil chileno".

Fecha de recepción: 13 de octubre de 2011

Fecha de aceptación: 5 de enero de 2012.

** Profesor Pontificia Universidad Católica de Valparaíso, Valparaíso, Chile, Doctor en Derecho por la Universidad Autónoma de Madrid, correo electrónico: alvaro.vidal@ucv.cl

*** Profesora Pontificia Universidad Católica de Valparaíso, Valparaíso, Chile, Doctora en Derecho por la misma Universidad, correo electrónico: maria.brantt@ucv.cl
} 


\section{1) INTRODUCCIÓN}

El presente trabajo tiene por objeto el análisis de la sentencia de la Corte Suprema de fecha 7 de septiembre de 2010, rol 1089-2009, a propósito del incumplimiento de la obligación de cuidado que recae sobre el establecimiento educacional respecto de sus estudiantes en virtud del contrato de educación.

Con dicho fin, en primer lugar describiremos los hechos del caso y las pretensiones de las partes, así como los aspectos más relevantes de la sentencia dictada tanto en primera como en segunda instancia, y aquella pronunciada por la Corte Suprema recaída en la casación en el fondo. Posteriormente, el análisis se centrará en una de las cuestiones fundamentales para la adecuada resolución del caso: la referida a la distinción del incumplimiento y la carga de la prueba del mismo; y la atribución de responsabilidad una vez establecido el incumplimiento. Seguidamente, comentaremos críticamente la sentencia, para finalizar con unas conclusiones.

\section{2) LOS HECHOS DEL CASO}

El demandante, don Enrique Netz Puschmann, celebró en el año 1989 un contrato de educación a favor de su hija menor de edad, con la sociedad educacional The Wessex School de Concepción.

Entre el 21 de agosto y el 11 de septiembre del ańo 2002, la hija del demandante, de entonces 17 ańos, se encontraba participando en la gira de estudios del curso al que pertenecía, actividad que tradicionalmente se realizaba en Inglaterra y Francia. El viaje se hizo en compañía de tres profesores y del rector del colegio. La gira se inició en Londres, desde donde se desplazaron a Stradford, Lam May, York y Glasgow. Luego el grupo se trasladó hasta Edimburgo, en Escocia. El día 8 de septiembre, antes de salir a un paseo planificado para dicha jornada, el rector del colegio acusó a la hija del demandante y a otra alumna de estar ebrias, razón por la cual ordenó que ambas permanecieran en el bus, sin compañía, durante todo el día, mientras los demás estudiantes proseguían con el itinerario previsto. Luego, dispuso la aplicación de la sanción consistente en el regreso inmediato de las dos alumnas a Chile, medida prevista en el reglamento de la gira de estudios que había sido aceptado por los apoderados de los estudiantes, entre ellos el demandante. Al llegar el grupo a la ciudad de Liverpool, se les informó que viajarían de vuelta a Chile el día 11 de septiembre, decisión que fue informada al padre de la menor y rechazada por este. No obstante ello, igualmente se embarcó a las menores solas en un vuelo con escala en Madrid y con destino final a Santiago, debiendo hacer 
todo el trayecto sin la compañía de un adulto, por cuanto los profesores y el rector del colegio permanecieron con el resto del grupo en el desarrollo de la gira de estudios.

\section{3) LAS PRETENSIONES DE LAS PARTES}

Don Enrique Netz Puschmann deduce demanda de indemnización de perjuicios por responsabilidad contractual en contra de la sociedad educacional The Wessex School fundada en los dańos causados por el incumplimiento por parte de ésta del contrato de educación celebrado a favor de su hija en razón de la aplicación de una medida disciplinaria exagerada, ilegal y sin debido proceso al hacerla regresar a Chile desde Inglaterra durante la gira de estudios, en forma anticipada, sin compañía de un adulto y en contra de sus expresas instrucciones. Solicita se condene a la demandada al pago de las siguientes sumas: a) pasaje a Europa: $\$ 676.948$; b) servicio terrestre: $\$ 1.821 .105$; c) US $\$ 1.000$ para gastos personales de la menor y los que se acreditaren durante el curso del juicio derivados de lo mismo y d) la suma de $\$ 50.000 .000$ por concepto de dańo moral sufrido o la suma que el tribunal determine, todo ello con reajustes e intereses.

Funda su demanda en que la medida disciplinaria aplicada a su hija fue arbitraria, dispuesta sin verificarse la efectividad de la conducta afirmada como la causante de la misma, y que en definitiva supuso poner a su hija en una situación de desprotección y notoria exposición al peligro, en circunstancias que por ser la gira de estudios una actividad extraprogramática, los representantes del colegio debían velar en todo momento por la seguridad y bienestar de su hija y sus compańeros, lo que no ocurrió, generándole importantes dańos desde el punto de vista sicológico, el que se vio acentuado por el trato hostil a que fue sometida la menor con posterioridad a los hechos. Agrega que la medida aplicada por el rector del colegio ha configurado un incumplimiento de su obligación de cuidado de la menor, emanada del contrato de prestación de servicios educacionales, y que la existencia de una cláusula de exoneración de responsabilidad en el reglamento de la gira de estudios no le priva de su acción para reclamar una indemnización, al haberle sido impuesta la suscripción como condición para la gira, y porque se trata de un derecho irrenunciable.

Por su parte, la demandada, al contestar la demanda solicitó su rechazo fundada en que los hechos en que ella se funda no son efectivos, y en la falta de requisitos y presupuestos necesarios para la responsabilidad contractual, atendido que no habría incumplimiento de obligación alguna, al no existir un comportamiento doloso o culposo, ni antijurídico, desde que le favorece una cláusula de exoneración de responsabilidad li- 
bremente consentida por las partes, de modo que se actuó en el legítimo ejercicio de una facultad aceptada por los apoderados. Tal consentimiento vendría dado por la suscripción, por parte del demandante, del reglamento de la gira de estudios. Agrega que tampoco habría perjuicio alguno que indemnizar, y en subsidio, que de existir alguno, habría sido causado por la propia menor.

En subsidio, opone la excepción de contrato no cumplido, fundada en el incumplimiento de parte de la menor de las reglas previamente establecidas para el desarrollo de la gira de estudios. Y por último, también en subsidio, para el caso que se determine que le cabe responsabilidad civil, alega que la indemnización debe rebajarse prudencialmente, porque la actora se expuso imprudentemente al daño.

\section{4) SENTENCIAS DE PRIMERA Y SEGUNDA INSTANCIA}

Por sentencia de 29 de marzo de 2005, el Tribunal de primera instancia rechazó en todas sus partes la demanda. Se funda en que si bien es un hecho no controvertido de la causa que las partes se encontraban ligadas por un contrato de prestación de servicios educacionales, la demandante no rindió prueba suficiente, tal como le correspondía conforme a las reglas del onus probandi, a fin de acreditar las estipulaciones de dicho contrato. Agrega que el reglamento de la gira de estudios no es suficiente para establecer las obligaciones de los contratantes, por referirse a una actividad puntual y que los demás medios de prueba aportados por la demandante tampoco son suficientes en tal sentido. Ańade que si bien se encuentra reconocida la relación contractual existente entre las partes, no consta de manera fehaciente, clara y precisa cuáles eran las obligaciones o deberes contraídos por cada uno de los contratantes.

Afirma que tal falta de prueba constituye un impedimento para acoger la demanda, atendido que en ella se imputa a la demandada el incumplimiento de una obligación contractual, pero no existe antecedente para saber exactamente el contenido de dicha obligación, y por ende, determinar si fue incumplida.

Agrega que teniendo en cuenta que el incumplimiento imputable al deudor es el primero de los requisitos para que surja la responsabilidad contractual, y considerando que la demandante alega incumplida una obligación de cuidado, la única prueba rendida por aquella para acreditar dicho incumplimiento, la declaración de un testigo, carece de todo mérito probatorio. Sostiene que por tanto, al no existir prueba suficiente que permita tener por establecido el incumplimiento de la obligación contractual en que habría incurrido la demandada, no cabe sino desestimar la demanda deducida en su contra. 
Y, a mayor abundamiento, afirma que debe considerarse que el propio actor, junto con los demás apoderados, consintió en la regla que prohibía el consumo de cualquier bebida alcohólica durante la gira de estudios, y que la infracción de la regla tendría como sanción el retorno inmediato a Chile del infractor, disponiéndose además que toda situación no prevista sería resuelta por los profesores encargados de la gira. De esta forma, los apoderados, y entre ellos, el demandante, delegaron en los profesores a cargo del grupo la decisión sobre la forma de aplicación de la sanción definida para dicha falta.

En contra de dicho fallo la demandada dedujo recursos de apelación y casación en la forma. La Corte de Apelaciones de Concepción, en sentencia de 11 de noviembre de 2005, rechazó el recurso de casación y confirmó el fallo de primera instancia.

De la lectura de la sentencia de primera instancia y de lo que aquí se expresa podemos advertir que el Tribunal del fondo rechaza la demanda fundado en que el acreedor demandante, no habría rendido prueba suficiente acerca de las obligaciones nacidas del contrato de educación y de su contenido, por lo que mal podía determinarse si hubo o no incumplimiento, presupuesto de la responsabilidad civil demandada. Luego de lo anterior -que corresponde al fundamento determinante del rechazo de la demanda- de modo innecesario y generando confusión, añade que el acreedor tampoco habría probado el incumplimiento de la obligación de cuidado en que apoya su demanda. Como se verá, hay dos puntos a dilucidar, la distribución de la carga de la prueba en materia de incumplimiento y, posteriormente, definido lo anterior, el objeto de la prueba que debe rendir cada una de las partes. Aquí, el sentenciador impone al acreedor la carga de acreditar la existencia de la obligación, siendo insuficiente la sola prueba de su fuente -el contrato-en tanto requiere también prueba sobre su contenido y, también, pone de su cargo la prueba del incumplimiento. Volveremos sobre el fundamento de la sentencia y estos dos puntos cruciales para la resolución del presente caso.

\section{5) MOTIVO DE CASACIÓN EN EL FONDO Y SENTENCIA DE LA CORTE SUPREMA}

El demandante interpone recurso de casación en el fondo fundado, entre otros vicios ${ }^{1}$, en la infracción de los artículos 1698 y 1547 inciso tercero del Código Civil, por cuanto del fallo recurrido se advierte que

1 El otro vicio de casación denunciado es que el Tribunal habría estimado que mediante la suscripción del reglamento de la gira de estudios se habrían derogado los principios contemplados en distintas normas del Código Civil que establecen el deber de cuidado inherente a todo contrato de educación. 
el sentenciador ha puesto de cargo del acreedor demostrar que existió incumplimiento y que además fue culpable, con lo que ha lesionado el principio del onus probandi, al invertir la carga de la prueba. Agrega que correspondía que el tribunal hubiese puesto de cargo de la demandada la justificación de que había cumplido totalmente sus obligaciones y que no había existido negligencia en la ejecución del contrato que ligaba a las partes.

Al resolver sobre la casación, la Corte Suprema, en sentencia de 7 de septiembre de 2010, declara que de los escritos fundamentales del juicio se advierte que no ha existido controversia en relación a la existencia del contrato de educación que liga a las partes. Agrega que en un contrato de tal naturaleza cobra especial relevancia el deber de cuidado que corresponde al prestador del servicio de educación, y que aun cuando no se conozca el articulado específico contenido en el contrato que liga a las partes, resulta que es propia de una convención de tal trascendencia dicha obligación de custodia. Citando la doctrina de dos autores declara que "el propietario de un establecimiento educacional asume no solo las obligaciones típicas que emergen de dicha relación, sino también una obligación de seguridad que consiste en mantener indemne la integridad física y espiritual del educando". Ańade que el deber de custodia se mantiene no solamente durante el tiempo que el alumno permanece en las instalaciones del establecimiento educacional, sino también durante aquel que se destina a otra clase de actividades, como son los viajes de estudio.

Así, la Corte Suprema, a partir de la ausencia de controversia entre las partes sobre la existencia del contrato de educación -fuente de la obligación que se alega incumplida- procede a llenarla de contenido e integra su prestación. La Corte considera la obligación de cuidado o custodia como uno de los efectos característicos de un contrato de educación. Se advierte un distanciamiento de la posición del Tribunal de primera instancia, que rehúye la tarea de interpretación integradora que le impone el propio Código civil en el artículo 1546, que, aunque no citado por la Corte Suprema, es el precepto que sirve de base para esta tarea ${ }^{2}$. La doctrina y la jurisprudencia hallan en algunos contratos como el de educación la fuente de estas obligaciones de seguridad y cuidado en el principio de la buena fe como creadora de deberes de conducta contractuales a partir de lo dispuesto por el citado artículo 1546 del Código Civil.

2 En tal sentido, Abeliuk afirma que en tarea de la interpretación del contrato, corresponde también la complementación del mismo, y cita al respecto la norma contenida en el artículo 1546 del Código Civil. Aвeliuk, René (2008) Las obligaciones, tomo I. Santiago: Editorial Jurídica de Chile, p. 118. Recogiendo la idea definir el alcance del contrato a partir del artículo 1546 del Código Civil se ha pronunciado recientemente la Corte de Apelaciones de San Miguel, en sentencia de fecha 16 de junio de 2001, identificador LP 50066. 
Sentado lo anterior, la Corte ańade que debe considerarse que el incumplimiento o cumplimiento imperfecto de las obligaciones hace nacer la responsabilidad contractual, la que entre sus requisitos tiene el incumplimiento, cumplimiento imperfecto o tardío por parte del deudor; así como la imputación del incumplimiento o culpabilidad. A ese respecto, declara que para resolver el caso deben hacerse ciertas precisiones en torno a la culpa contractual, en el sentido que el inciso tercero del artículo 1547 permite concluir que la ley presume que la infracción de toda obligación contractual deriva de la culpa o falta de diligencia del deudor, y que a partir de ello, el acreedor no está obligado a probar la culpa sino que el deudor debe demostrar que no incurrió en ella, probando la debida diligencia empleada en el cumplimiento (considerando octavo).

Luego, agrega que respecto al reproche de casación de haberse invertido la carga de la prueba con la consecuente infracción del artículo 1698 del Código Civil, debe considerarse que como la culpa se presume, correspondía al demandado justificar que agotó el deber de diligencia exigible. De esta forma, al razonar los jueces del fondo en un sentido contrario, exigiéndole al actor una carga que no le ha sido impuesta, se ha vulnerado el artículo 1698 del Código Civil (considerando undécimo).

Asimismo, afirma que a partir de los antecedentes que obran en el proceso resulta que el colegio demandado no pudo tomar una decisión como la de enviar a la menor hija del demandante desde Inglaterra a Chile con escala en España y sin la compañía de un adulto responsable, sin haber incumplido su obligación de custodia. Rechaza que tal medida pueda justificarse como una sanción disciplinaria pues una disposición de este tipo jamás puede arriesgar la seguridad de los menores (considerando duodécimo). Agrega que las probanzas rendidas por la demandada no permiten acreditar de manera alguna el cumplimiento de la obligación que le compete. Y por último que, conforme a lo anterior, se hace evidente la infracción del inciso tercero del artículo 1547 del Código Civil, por cuanto los sentenciadores desatendieron la circunstancia que la parte demandada no aportó probanza alguna para demostrar el correcto y oportuno cumplimiento de la obligación de vigilancia y supervisión que asumió en virtud del contrato, a pesar que obraba a favor de la demandante una presunción simplemente legal de culpabilidad (considerando decimotercero).

Finaliza la Corte afirmando que la errónea aplicación de las normas constatada ha tenido influencia sustancial en lo dispositivo del fallo, pues con base a ella se determinó por los jueces del grado la inexistencia de un incumplimiento contractual de la demandada (considerando decimocuarto). En razón de ello acoge el recurso de casación, invalidando la sentencia recurrida y dictando un fallo de reemplazo que acoge la demanda. 
Si bien la Corte Suprema no califica la obligación del demandado como una de medios, de la lectura de la sentencia y de las afirmaciones aludidas se infiere que la considera como una de esta especie, al entender que el colegio demandado cumplía su obligación desplegando la debida diligencia y a este le correspondía la carga de acreditarlo en juicio, cosa que no hizo. Si bien estamos de acuerdo con la calificación que hace la Corte Suprema, estimamos -como diremos luego- que interpreta y aplica de modo incorrecto la norma del inciso tercero del artículo 1547 del Código Civil al considerar que este precepto contendría una presunción de culpa como sinónima de incumplimiento contractual, que la demandada debía revertir probando el cumplimiento. Ahora bien, podría discutirse, incluso en el mismo fallo, tal carácter de obligación de actividad si se la califica como una de seguridad perteneciente al género de las de resultado. No obstante, dicha discusión no alteraría la decisión de la Corte Suprema porque el demandado igualmente no habría acreditado el cumplimiento de su obligación. A nuestro juicio, cualquiera sea la clase de obligación, las reglas del onus probandi y de responsabilidad son las mismas. Como explicaremos a continuación, su incumplimiento queda sujeto a un mismo régimen.

\section{6) FUNCIONALIDAD DEL RÉGIMEN DE RESPONSABILIDAD CONTRAC- TUAL EN EL CÓdigo CiVIL Y DiSTRIBUCIÓN DE LA CARGa DE LA PRUEBA EN MATERIA DE INCUMPLIMIENTO}

Para analizar lo resuelto en este caso es preciso detenerse previamente en dos cuestiones vinculadas directamente con el asunto debatido en el mismo, como son las reglas que rigen la responsabilidad por incumplimiento contractual en nuestro Código Civil; y aquellas sobre carga de la prueba del cumplimiento e incumplimiento, a objeto de imponer al deudor la obligación de indemnizar a favor del acreedor.

En lo que refiere a la responsabilidad contractual, pese a la falta de reconocimiento positivo no es posible negar la existencia en el tráfico de obligaciones de medios y de resultado ${ }^{3}$. Aceptando tal distinción, hemos

3 La necesidad de reconocer tal distinción resulta de la sola constatación de la diversa configuración de la prestación en uno y otro caso. En tal sentido: Vidal Olivares, Álvaro (2010) "Incumplimiento y atribución de responsabilidad en las obligaciones de medio y de resultado (a propósito de una sentencia de la Corte Suprema No ingreso 1771-2008)", en Estudios de Derecho Civil V, Santiago: Abeledo Perrot, p. 578; García González, Alejandro (2002) Responsabilidad civil contractual. Obligaciones de medios y de resultado. Santiago: Editorial Cono Sur, p. 31; Pizarro Wilson, Carlos (2009) "La culpa como elemento constitutivo del incumplimiento", en Revista de Derecho PUCV, XXXI 2, p. 258; Peńailillo Arévalo, Daniel (2003) Obligaciones. Teoría General y Clasificaciones. La resolución por incumplimiento. Santiago: Editorial Jurídica de Chile, p. 227. En Espańa, 
sostenido que cualquiera sea la obligación incumplida la regla de responsabilidad es idéntica, la del artículo 1547, que no formula distinción alguna ${ }^{4}$.

Es indudable que para nuestro legislador el punto de partida de la responsabilidad civil es el incumplimiento, que al presumirse imputable al deudor le impone la obligación de indemnizar, sin diferenciar la clase de obligación concernida. Tal regla se induce del inciso tercero del artículo 1547 y consiste en que establecido que sea el incumplimiento corresponde al deudor la prueba de una causa de exoneración de responsabilidad, considerando para tal efecto la diligencia que le era exigible.

Ahora bien ¿qué diligencia debe acreditar el deudor en caso de incumplimiento y con qué finalidad? La diligencia a la que alude el inciso tercero del artículo 1547 corresponde a una actividad externa y accesoria a la prestación misma, que debe desplegar el deudor frente a aquellos hechos o sucesos externos que puedan sobrevenir durante la ejecución de la obligación, afectando o amenazando el cumplimiento, y que tiene por objeto resistirlos o superarlos, de modo que el proyecto de prestación se realice y el acreedor satisfaga su interés. Como expresa Díez Picazo, la diligencia promotora comprende "las actividades de preservación y de evitación de los eventos que puedan ponerla en peligro [la prestación], causar dańos o hacerla imposible" 5 . Es lo que la doctrina ha denominado "diligencia promotora del cumplimiento", y que se manifiesta en una actividad de carácter instrumental al mismo ${ }^{6}$. La conducta desplegada por

entre otros: Jordano Fraga, Francisco (1991) "Obligaciones de medios y de resultado (A propósito de alguna jurisprudencia reciente)", Anuario de Derecho Civil, volumen 44, número 1, pp. 20 y ss; Loвato Gómez, J.M. (1992) "Contribución al estudio de la distinción entre las obligaciones de medios y las obligaciones de resultado", Anuario de Derecho Civil, volumen 45, número 2, p. 653. En Francia Faure Abbad, Marianne (2003) Le fait générateur de la responsabilité contractuelle. París: Poitiers, p. 244.

4 Vidal Olivares (2010) 581, y en Vidal Olivares, Álvaro (2007) "El incumplimiento de obligaciones con objeto fungible y los remedios del acreedor afectado. Un intento de relectura de las disposiciones del Código Civil sobre incumplimiento”, en El Código Civil de Chile (1885-2005). Trabajos expuestos en el Congreso Internacional celebrado para conmemorar su promulgación. Santiago: Lexisnexis, p. 514 y ss.; Brantt Zumarán, María Graciela (2010) El caso fortuito y su incidencia en el derecho de la responsabilidad civil contractual. Concepto y alcance del caso fortuito en el Código Civil chileno. Santiago: Abeledo Perrot, pp. 206 y ss.

5 Dífz-Picazo, Luis (2008) Fundamentos del Derecho Civil Patrimonial: Las relaciones obligatorias. Navarra: Editorial Civitas, volumen II, sexta edición, p. 122.

6 La denominación de diligencia promotora fue dada en Espańa por BAdosa Coll, Ferrán (1987) La diligencia y la culpa del deudor en la obligación civil. Bolonia: Publicaciones del Real Colegio de Espańa, pp. 61 y ss. quien precisamente la describe como una conducta de carácter instrumental que se diferencia materialmente de la prestación debida. Reconociendo esta función de la diligencia, aunque no siempre empleando dicha denominación, se ubican en Chile Baraona GonzÁlez, Jorge (1997) "Responsabilidad contractual y factores de imputación de dańos: apuntes para una relectura en clave objetiva”, Revista Chilena de Derecho, No 24, tomo I, p. 167; Peńailillo (2003) 497 y 
el deudor en observancia de esta diligencia no se identifica con el cumplimiento, mas es necesaria para que este se verifique, es una herramienta para su concreción ${ }^{7}$, y adquiere especial interés cuando este no se produce. En efecto, el deudor debe acreditar que pese a haber empleado tal diligencia frente al suceso extrańo, el incumplimiento igualmente tuvo lugar, pudiendo así exonerarse de responsabilidad.

Entendemos que el comentado inciso tercero vincula necesariamente la diligencia y el caso fortuito como causa de exoneración de la responsabilidad; la primera permite medir la irresistibilidad del suceso o hecho en que consiste el segundo ${ }^{8}$. La carga de prueba de la diligencia impuesta al deudor, que permite construir la presunción de imputabilidad sirve de medio para la configuración del caso fortuito, que según la misma disposición, excluye su responsabilidad por los dańos que el incumplimiento cause al acreedor. Lo anterior coincide con la regla del inciso segundo del artículo 1547 que prevé como única causa de exoneración al caso fortuito al disponer que "el deudor no es responsable del caso fortuito", excluyendo la posibilidad que la sola prueba de la diligencia libere al deudor de responsabilidad.

Por consiguiente, de la interpretación que se hace de los dos incisos del precepto en estudio, fluye que el deudor debe probar que le ha sobrevenido un hecho extrańo, que afectó su cumplimiento, imprevisible al contratar y que no pudo resistir, no obstante haber empleado la diligencia promotora del cumplimiento según lo expresado precedentemente.

Esta diligencia promotora pasa desapercibida cuando hay cumplimiento conforme al contrato, pero adquiere importancia en caso de incumplimiento. Se trata, entonces, de una diligencia que interesa en el plano de la atribución de responsabilidad.

La comprensión de la diligencia que aquí se afirma permite la construcción de un caso fortuito de carácter relativo, diferenciado de la im-

ss; Domínguez Águila, Ramón (2008) "La culpa en el derecho civil chileno. Aspectos generales", Revista Anales de Derecho UC. Temas de responsabilidad civil, no 3, pp. 116 y ss. y p. 126. En Espańa, entre otros: Díez-Picazo (2008) 121; Lobato Gómez (1992) 668 y 716; Carrasco Perera, Ángel Francisco (1989) "Artículo 1104 Código Civil", en Comentarios al Código Civil y Compilaciones Forales. Madrid: n/d, pp. 8 y ss. En Italia: Mengoni, Luigi (1954) "Obbligazione 'di risultato' e obbligazione 'di mezzi”, Rivista dil DirittoCommerciale, no I y II, p. 58; Breccia, Umberto (1968) Diligenza e buona fede nell'attuazione del raporto obligatorio. Milán: Editorial A. Giuffrè, p. 132.

7 En este sentido, Badosa expresa que la diligencia promotora, a diferencia de la integradora "no se caracteriza por su aptitud de incorporación a la actividad sino por su eficacia causal" respecto de la prestación. BAdosa (1987) 175.

8 Carrasco, a partir de en que el Código Civil español los elementos que definen el caso fortuito son la imprevisibilidad e inevitabilidad, al referirse a la diligencia y su negación, la culpa, afirma que los elementos para dicho juicio son la previsibilidad e inevitabilidad. Carrasco Perera (1989) 8. A su vez, Jordano Fraga afirma que esta función de la diligencia pretende preservar la posibilidad de cumplimiento frente a eventos sobrevenidos. JORDANO FRAGA (1991) 32 y ss. 
posibilidad absoluta de cumplimiento. El caso fortuito tiene eficacia exoneratoria de responsabilidad cualquiera sea la obligación y no la extingue salvo que integre el supuesto de la imposibilidad sobrevenida no imputable ${ }^{9}$. Se relativiza la conducta exigible a los diversos operadores del tráfico: lo que tiene derecho a esperar el acreedor de cada uno de ellos frente a la intervención de un hecho extraño dependerá de las circunstancias del caso y la economía del contrato celebrado.

Ahora bien, si el deudor prueba que cumplió su obligación no es propio hablar de exoneración de responsabilidad, sino de extinción de la obligación por medio del pago. Esta afirmación cobra relevancia para las obligaciones de medios o de actividad, en las que la diligencia cumple dos funciones: además de la promotora del cumplimiento, actúa como integradora de la prestación.

En efecto, junto a la diligencia promotora del cumplimiento se ubica la denominada diligencia integradora de la prestación, cuyo ámbito propio es el de las obligaciones de medios ${ }^{10}$, aquellas "cuya prestación consiste en el despliegue de una actividad del deudor dirigida a proporcionar cierto objeto, interés o resultado al acreedor", pero sin que ese resultado esté "in obligatione"11. En ellas la obtención del resultado no es necesaria para liberar al deudor que solo se obliga a una actuación correcta: aquella que realizaría una persona diligente en su misma situación ${ }^{12}$. La conducta que integra la prestación se define acudiendo a reglas técnicas o profesionales y su realización equivale al cumplimiento. Así, la diligencia integradora llena de contenido a la prestación debida ${ }^{13}$ que consiste en una actividad diligente ${ }^{14}$.

En las obligaciones de medios, por sus especiales características, las partes excepcionalmente definen con precisión y plenitud el objeto de la obligación, la prestación comprometida por el deudor ${ }^{15}$. Es el juez quien, al momento de resolver un conflicto de cumplimiento o incumplimiento,

9 Sobre el carácter relativo del caso fortuito: BrantT Zumarán (2010) 151 y ss.

10 Betti afirma que en esta clase de obligaciones la actividad debida por el deudor se mide o controla según un criterio de diligencia, necesario para determinar si ha habido o no cumplimiento. BetTi, Emilio (1970) Teoría General de las Obligaciones. Madrid: n/d, p. 142.

11 Peńailillo Arévalo (2003) 223-224. En un sentido similar, Lobato Gómez afirma que en la obligación de medios "la prestación debida consiste en el despliegue de una actividad del deudor dirigida a proporcionar, de forma mediata, la satisfacción del interés del acreedor, o lo que es lo mismo, en el desarrollo de una conducta diligente encaminada a conseguir el resultado previsto por el acreedor al contratar”, agregando luego que ese resultado eso sí, no forma parte de la prestación. Lobato Gómez, (1992) 653.

12 Vidal Olivares (2010) 578.

13 Díez-Picazo (2008) 121.

14 Lobato seńala que en ello consiste el objeto de la obligación en aquellas de medios. LовAто Gómez (1992) 657.

15 Vidal Olivares (2010) 579. 
debe integrar la prestación acudiendo a la lex artis o reglas técnicas o profesionales, según el caso. Esta tarea, que le viene impuesta al juez, tiene su fundamento último en el artículo 1546 del Código civil, aplicable a toda clase de obligación ${ }^{16}$.

De esta forma se advierte que estas dos diligencias están situadas en planos diversos, la integradora en el de la configuración del contenido de la prestación y, consiguientemente, del cumplimiento e incumplimiento de la obligación; en cambio, la promotora se sitúa en el de la responsabilidad por el incumplimiento al actuar, o como criterio de imputación subjetiva, o como de exoneración de responsabilidad cuando interviene un caso fortuito. La primera, permite definir el contenido de la obligación -la prestación-, dotarla de contenido, y por tanto, establecer, contrastando este contenido con la actividad desplegada por el deudor, si este cumplió o no la obligación; la segunda, en cambio, establece aquel comportamiento que debía desplegar el deudor para evitar y superar obstáculos ajenos e imprevistos que pongan en riesgo la satisfacción del interés del acreedor. Por consiguiente, en las obligaciones de medios o mera actividad el no empleo de la diligencia debida, aunque aparezca como contradictorio, estrictamente corresponde a su incumplimiento; ello, a pesar que suele calificársele como "culpa", por oposición o en cuanto antónimo de la expresión diligencia que sirve para denominarla ${ }^{17}$. Siendo así, en esta clase de obligaciones, aunque se establezca el incumplimiento -entendido como falta de diligencia- igualmente el deudor podría exonerarse de responsabilidad acreditando el caso fortuito en los términos que hemos explicado; actuando, entonces, la diligencia en sus dos funciones ${ }^{18}$ y distinguiéndose claramente el plano en que actúa cada una de ellas.

Habiendo diferenciado estas dos funciones de la diligencia, podemos ahora afirmar que, cualquiera sea la obligación de que se trate, el presupuesto de la responsabilidad será siempre el incumplimiento, que en las obligaciones de medios consiste en la falta de la diligencia integradora y en las de resultados en la constatación de su no consecución. Entonces, solo una vez establecido el incumplimiento de cualquiera de ellas, actúa

Al respecto, véase Vidal Olivares, Álvaro (2010) La construcción de la regla contractual en el derecho civil de los contratos, en Incumplimiento contractual, resolución e indemnización de daños. Bogotá: $\mathrm{n} / \mathrm{d}$, pp. 33 y ss.

17 Al respecto, cabe destacar lo afirmado por Badosa, en el sentido que la infracción de la diligencia integradora es el incumplimiento de la obligación, sin que pueda ser calificada de culpa. Badosa Coll (1987) 168. En sentido similar Morales Moreno afirma que tratándose de las obligaciones de medios la culpa del deudor no es otra cosa que el propio incumplimiento. Morales Moreno, Antonio Manuel (2010) Incumplimiento del contrato y lucro cesante. Madrid: n/d, p. 30.

18 Reconocen que en esta clase de obligaciones la diligencia opera en sus dos funciones: Jordano Fraga (1991) 31, 32, 36, 41, 58; Carrasco Perera (1989) 5; Del Olmo Guarido, Natalia (2004) El caso fortuito: su incidencia en la ejecución de las obligaciones. Doctrina y jurisprudencia. Navarra: n/d, p. 189. 
la regla de atribución de responsabilidad que impone al deudor la obligación de indemnizar salvo la prueba del caso fortuito que envuelve la apreciación de la observancia de la diligencia promotora.

Habiendo delimitado los dos planos de la responsabilidad civil contractual -incumplimiento y atribución de responsabilidad- la pregunta que surge se refiere al onus probandi o a la carga de la prueba en el juicio de incumplimiento. Al respecto, la disposición del Código civil aplicable es la del artículo 1698 que prescribe "incumbe probar las obligaciones o su extinción a quien alega aquellas o ésta". Del tenor literal de la norma la doctrina sostiene que sobre el acreedor pesa la carga de probar la existencia de la obligación, bastándole alegar que el deudor la ha incumplido; $y$, el deudor debe probar el cumplimiento de la obligación, que equivale a su extinción por medio del pago ${ }^{19}$. Claramente, esta interpretación no ofrece problema alguno cuando se ha producido una falta de cumplimiento, en que tratándose de un hecho negativo resulta lógico que no recaiga sobre el acreedor la carga de la prueba del mismo y que, por el contrario, sí pueda exigirse al deudor que acredite su cumplimiento. Sin embargo, distinto es el caso de los cumplimientos imperfectos. En ellos el deudor prueba formalmente que cumplió y el acreedor alega la falta de conformidad de ese cumplimiento con lo pactado, es decir, el incumplimiento. Hay un cumplimiento aparente respecto del cual el acreedor discute y niega su insuficiencia para extinguir la obligación el acreedor. En estos supuestos hemos sostenido que resulta necesario alterar la comprensión tradicional de la regla del onus probandi, de modo de poner de cargo del acreedor la prueba del cumplimiento imperfecto dado que en el fondo estaría afirmando la subsistencia de la obligación pese a la actividad del deudor, y ello supondría la aplicación de la primera parte de la regla del artículo $1698^{20}$. Ahora bien, no obstante mantener lo anterior, una lectura desde la noción de incumplimiento entendido como la falta de coincidencia entre el objeto ideal de la obligación -que corresponde a la prestación interpretada e integrada por el juez- y el objeto real, esto es, aquello efectivamente realizado por el deudor, lleva a hacer una precisión en torno cómo debiera funcionar en definitiva la regla del citado artículo 1698 en lo que refiere a esta clase de incumplimientos.

En efecto, es tarea del juez construir la regla contractual concreta y aplicarla para la resolución del conflicto en torno al cumplimiento o incumplimiento del deudor. Para este objeto, el juez interpreta e integra

Peńailillo (2003) 228; Fueyo Laneri, Fernando (2004) Cumplimiento e incumplimiento de las obligaciones, 3ra. edición. Santiago: Editorial Jurídica de Chile, pp. 402 y ss.; Abeliuk (2008) 506; Pizarro Wilson (2009) 260.

20 Vidal Olivares (20io) 575 y ss. Brantt Zumarán, María Graciela (2011) "La prueba del cumplimiento imperfecto en las obligaciones de medios y de resultado", en Estudios de Derecho Civil, en prensa. 
la prestación -el objeto ideal- y lo hace para posteriormente contrastarlo con la actividad que ha sido acreditada por el deudor que alega haber cumplido con su obligación. Ahora bien, para que el juez pueda realizar esa labor, es fundamental la actividad probatoria tanto del acreedor como del deudor, pues a partir de ambas él podrá concluir si ha existido o no una disconformidad entre lo convenido y lo ejecutado y probado por el deudor.

De esta forma, cualquiera sea la manifestación del incumplimiento, siempre pesa sobre el deudor la carga de probar el cumplimiento y que, por tanto, ha extinguido su obligación. Pero si lo alegado por el acreedor es un cumplimiento imperfecto -en tanto ello supone que la obligación todavía existe porque el pago alegado por el deudor no ha tenido eficacia extintiva- le corresponde a aquel probar que se ha ejecutado una prestación no conforme y aquello pasa porque el acreedor pruebe el contenido exacto de la obligación, los distintos extremos de la misma, en especial, los que considera infringidos. En rigor, tiene vigencia la regla del artículo 1698 en su integridad, produciéndose una suerte de cruce de prueba que deberá permitir al juez arribar a la convicción acerca de si ha habido o no incumplimiento. Esta interpretación nos conduce a una especie de prueba dinámica, puesto que el acreedor junto con acreditar la existencia de la obligación y su contenido, debe justificar la desviación con relación a este último; y el deudor por su parte debe justificar la realización de la conducta debida según la construcción hecha por el juez.

$\mathrm{Si}$ a partir de la prueba rendida por las partes estima que hay coincidencia entre el objeto ideal y el real, se tendrá por acreditado el cumplimiento y la demanda será rechazada por no concurrir el presupuesto de la responsabilidad, esto es, el incumplimiento. En cambio, si concluye lo contrario, se dará lugar a la demanda, salvo que el deudor pruebe, conforme el artículo 1547 inciso tercero, la intervención de un caso fortuito.

En relación a cuál es el alcance de la prueba que debe rendir el acreedor en estos casos, resulta que será fundamental aquella que refiera al contenido de la prestación cuya realización imperfecta alega, de modo de asegurarse que el objeto ideal que fije el juez sea el que él afirma y, consiguientemente, se concluya la falta de coincidencia con aquello ejecutado por el deudor. En tal sentido, cabe citar lo afirmado por la Corte Suprema, en sentencia de 1 de enero de 2010, que declara "Que de acuerdo a lo establecido en el artículo 1698 del Código Civil, "incumbe probar las obligaciones o su extinción al que alega aquellas o ésta”. De este modo, era de cargo del actor probar la existencia del contrato que invoca como fundamento de su pretensión así como el contenido del mismo -lo que se tuvo como un hecho de la causa- y del demandado, haberse extinguido su obligación -pagar el precio acordado-, en este caso, por haber operado la excepción de contrato no cumplido por él invocada, lo que no ha 
ocurrido en autos". Quiere decir, entonces, que la Corte Suprema, en este caso, extiende la carga de la prueba al contenido de la obligación, lo que en definitiva resulta fundamental en supuestos de cumplimientos imperfectos.

Ahora bien, solo una vez establecido el incumplimiento en la forma señalada, y cualquiera sea la obligación concernida-de medios o de resultado-, resulta aplicable el inciso tercero del artículo 1547, que imputa responsabilidad al deudor por los dańos derivados de tal incumplimiento, salvo que este acredite un caso fortuito, lo que implica necesariamente la prueba de la diligencia promotora del cumplimiento. Como se ha explicado, la sola prueba de esta diligencia no exonera, hace falta que el incumplimiento establecido tenga su causa en un impedimento o hecho extraño.

Por consiguiente, al dar una ubicación a las normas sobre carga de la prueba, se advierte que la del artículo 1698 se sitúa en el primer plano, el del cumplimiento e incumplimiento; y la del inciso tercero del artículo 1547 en el segundo, de la responsabilidad o imputación subjetiva del incumplimiento. Por lo tanto, no es exacto, ni que la segunda norma constituya una excepción a la primera, ni que ella sea una aplicación concreta de la misma cuando se trate de obligaciones de medios ${ }^{21}$ : ambas rigen ámbitos diversos ${ }^{22}$.

21 Peñailillo (2003) 229, y en "Responsabilidad contractual objetiva", en Estudios de derecho civil IV. Santiago: Abeledo Perrot, p. 488; Pizarro Wilson (2009) 263.

22 Y en cada uno de tales ámbitos, cada regla tiene alcance general, con independencia de que se trate de una obligación de medios o una de resultado. En tal sentido, y por lo ya señalado, no compartimos la idea de que el artículo 1547 se restrinja en su aplicación a un solo tipo de obligación. Ni que se refiera exclusivamente a las obligaciones de medios, en tanto la diligencia no jugaría rol alguno o carecería de importancia en las obligaciones de resultado, como lo afirma PIZARRO WILSON (2009) 265 y en PIZARRO WiLSON, Carlos (2009) "Diligencia, incumplimiento y exoneración de responsabilidad. Comentario a sentencia Corte Suprema no ingreso 1.771-2007”, en Estudios de Derecho Civil V. Santiago: Abeledo Perrot, p. 590 y ss.; ni que excluya a las obligaciones de medios, al menos en lo que se refiere a la presunción de culpa que se extrae del inciso tercero de dicha disposición, como lo sostiene Domínguez Hidalgo, Carmen, (2010) "El problema de la culpa presunta contractual y las obligaciones de medios y de resultado: sus implicancias para la responsabilidad médica", Responsabilidad médica, Cuadernos de Análisis Jurídico, colección derecho privado VI, pp. 24 y ss. La autora, siguiendo a Domínguez Águila, y a propósito de la responsabilidad médica, postula que tratándose de las obligaciones de medios no sería aplicable la presunción de culpa del deudor, de modo que el acreedor debe probar la culpa que alega, acercando así lo que sucede en sede contractual y extracontractual. Por su parte, cabe destacar que si bien Domínguez Águila efectivamente rechaza el carácter general atribuido al inciso tercero del artículo 1547 -y lo hace fundamentalmente a partir de lo previsto en el artículo 2158 del Código Civil, afirmando que en tal caso la ley no presume la culpa del profesional-, luego reconoce que en tales obligaciones, la presunción puede operar en la medida que se haya acreditado el incumplimiento. DomínguEZ ÁGUILA, Ramón (2008) "La culpa en el derecho civil chileno. Aspectos generales", en Revista Anales de Derecho UC. Temas de responsabilidad civil, no 3, pp. 124 y ss. 
¿Qué consecuencias prácticas se siguen de esta lectura del artículo 1698 para los cumplimientos imperfectos?

La primera consiste en que si el Tribunal rechaza la demanda porque el acreedor no probó el incumplimiento, no incurriría en infracción al artículo 1698 del Código civil, por lo que no se daría origen a un vicio de casación en el fondo y a la invalidación del fallo respectivo por esta causa. Seguidamente, si el Tribunal rechaza la demanda porque el acreedor no acreditó la imputabilidad subjetiva del incumplimiento -la culpa- procedería la casación en el fondo por infracción al artículo 1547 inciso tercero. Se diferencian claramente los planos en que actúan ambos preceptos.

Finalmente, si el Tribunal rechaza la demanda por entender que el deudor cumplió y el acreedor insiste en el cumplimiento imperfecto, solo le quedaría recurrir de casación en contra de la sentencia por errónea interpretación del contrato, dándose por normas infringidas los artículos 1546, 1560 y ss. y, en definitiva, el artículo 1545, todos del Código Civil, así como las normas reguladoras de la prueba ${ }^{23}$.

\section{7) APLICACIÓN DE LA TESIS ANTERIOR AL CASO Y ANÁliSIS DE LA SENTENCIA DE LA CORTE SUPREMA}

A partir de lo expresado en la sección anterior procede formularse dos preguntas. La primera ¿̇es acertada la sentencia de la Corte Suprema?; $y$, de ser afirmativa la respuesta, jes correcto su fundamento y el razonamiento del Tribunal?

Previo al análisis de la sentencia de la Corte Suprema, creemos necesario pronunciarnos sobre la sentencia de primera instancia confirmada por la Corte de Apelaciones de Concepción. La sentencia, como aparece de lo expresado en la sección III del presente trabajo, fundamenta el rechazo de la demanda en la falta de prueba de la obligación alegada como incumplida y de su contenido, al no haber acreditado la existencia de una obligación de cuidado impuesta por el contrato de prestación de servicios educacionales; y ańade que también debía rechazarse porque el acreedor no rindió prueba suficiente sobre el incumplimiento alegado. Desde luego, el Tribunal a quo incurre en un error al fundamentar la sentencia puesto que o la rechaza por falta de prueba de la existencia de la obligación o por ausencia de prueba del incumplimiento. El segundo fundamento es innecesario y no solo eso, es contradictorio con el primero. Todo incumplimiento presupone lógicamente la existencia de una obligación. De haberse fundado correctamente la sentencia, esto es, en la ausencia de prueba de la existencia y contenido de la obligación conforme 
el artículo 1698 del Código Civil, la sentencia igualmente hubiera sido susceptible de casación en el fondo por errónea interpretación del contrato e infracción del artículo 1545 del mismo cuerpo legal. El contenido de la obligación -la prestación-, debe fijarlo el juez por mandato de los artículos 1546 y 1560 y siguientes; más aún si no existió controversia sobre la existencia del contrato, como lo reconoce el propio sentenciador.

Sin embargo, el demandante deduce recurso de casación en el fondo apoyándose en el segundo fundamento de rechazo de la demanda, esto es, la infracción de las reglas sobre la carga de la prueba de los artículos 1698 y 1547 , inciso $3^{\circ}$ por cuanto el Tribunal invierte la carga de la prueba del cumplimiento que corresponde al deudor demandado.

Tratándose de la sentencia de la Corte Suprema, volvamos a las dos preguntas antes formuladas. Respecto de la primera interrogante, el fallo no es acertado al acoger el recurso de casación en el fondo e invalidar la sentencia recurrida. La Corte Suprema, a partir de la prueba del contrato de prestación de servicios educacionales, integra su contenido y, estimamos que aunque no lo expresa, entiende que la obligación de cuidado o custodia, que va incorporada en todo contrato de este tipo, es una obligación de medios que se satisface mediante el empleo de la debida diligencia por parte del deudor demandado. Lo anterior por cuanto precisamente vincula su cumplimiento e incumplimiento con el empleo de dicha diligencia y como el deudor no lo acreditó en el juicio procede a acoger la demanda en todas sus partes. En concreto, la Corte Suprema resuelve que la sentencia recurrida invierte la carga de la prueba al rechazar la demanda por no haber el acreedor demandante probado el incumplimiento, en circunstancias que corresponde al deudor acreditar el cumplimiento de la obligación. Esa inversión constituye según la Corte una infracción a los artículos 1698 y 1547 , inciso $3^{\circ}$ que influye sustancialmente en lo dispositivo del fallo. Sin embargo, a partir de lo expresado precedentemente, sin perjuicio de recaer sobre el deudor el peso de la prueba del cumplimiento perfecto de su obligación de cuidado, es perfectamente procedente cargar al acreedor con la prueba del incumplimiento invocado como fundamento de la demanda, por cuanto por tratarse de un cumplimiento imperfecto, implica que el acreedor afirma que la obligación no se ha extinguido, por el contrario, que existe aún, con lo que le resulta aplicable la primera parte del artículo 1698, que no se agota simplemente con la prueba sobre la existencia del contrato, sino de aquello que mantiene vigente la obligación, que es el incumplimiento. Cuestión distinta es que se deduzca igualmente del fallo que la Corte Suprema tuvo por acreditado el incumplimiento del colegio demandado, lo que se desprende de su considerando duodécimo, difiriendo así del criterio de los jueces del fondo. En rigor, al máximo tribunal entiende infringida igualmente la norma que regula carga de la prueba, no obstante que por tratarse de un supuesto de 
cumplimiento imperfecto, no podría aplicarse en el sentido en que comúnmente ha sido interpretada.

A la segunda pregunta, creemos que el Tribunal de casación al fundamentar su decisión confunde los dos planos que hemos distinguido en la sección anterior, esto es, cumplimiento e incumplimiento y atribución de responsabilidad, y ello le lleva a delimitar erróneamente el ámbito de aplicación de las normas que da por infringidas para acoger el recurso e invalidar la sentencia recurrida.

En efecto, de acuerdo a la lectura que hacemos de los preceptos concernidos, la Corte Suprema debió haber justificado su decisión únicamente en la infracción del artículo 1698 del Código Civil, pues la cuestión debatida se centra en la prueba del cumplimiento e incumplimiento de la obligación, esto es, respecto del presupuesto de la responsabilidad civil contractual, de cuya concurrencia depende la aplicación del artículo 1547 inciso tercero, que, como se ha reiterado, refiere a la imputación subjetiva del incumplimiento ya establecido.

Tal confusión se desprende de lo expresado en los considerando octavo, undécimo y decimotercero del fallo de casación. En el octavo, con el que principia el análisis del incumplimiento y la culpa contractual, el Tribunal, a partir del inciso tercero del artículo 1547 del Código Civil, precisa que el legislador considera que la infracción de toda obligación es imputable a culpa del deudor y que el deudor debe demostrar que no incurrió en culpa, probando el debido cuidado o diligencia en el cumplimiento de la obligación. De los términos empleados por la Corte Suprema pareciera que la discusión estaría centrada en la culpa del deudor y no en el incumplimiento mismo. Sin embargo, en los considerandos posteriores (undécimo y decimotercero) identifica el empleo de la diligencia con el cumplimiento y la ausencia de la misma con el incumplimiento.

Puede deducirse, porque no lo explicita, que la Corte Suprema recurre al precepto en cuestión para fundamentar su fallo porque lo considera aplicable a la prueba del cumplimiento de las obligaciones de medios, desvinculándolo del contexto del precepto, cuál es, el de la responsabilidad y exoneración de la misma, en la que como hemos dicho solo incide la diligencia promotora del cumplimiento en términos tales que el deudor, establecido que sea su incumplimiento por el Tribunal, solo puede exonerarse de responsabilidad acreditando el caso fortuito. Ello denota que la afirmación de la infracción del inciso tercero del artículo 1547 vendría dada por la confusión de los planos antes explicados en que incurre el Tribunal. 


\section{CONCLUSIÓN}

Creemos que con este análisis se arroja claridad al régimen aplicable en materia de atribución de responsabilidad y carga de la prueba por incumplimiento a las obligaciones de medios, régimen que no difiere de aquel aplicable al incumplimiento de las obligaciones de resultado. En ambas, en casos de cumplimientos imperfectos la carga de la prueba recae sobre el acreedor, sin perjuicio de la prueba que ha de rendir el deudor, de modo tal que será la actividad probatoria de ambas partes lo que permitirá al juez resolver la controversia, de forma que si se concluye que hubo incumplimiento, éste le atribuirá, por regla general, responsabilidad al deudor, salvo la prueba del caso fortuito que se rige por el, tantas veces citado, inciso tercero del artículo 1547. La transcendencia de la distinción refiere a la fijación del contenido de la prestación, a la forma que se manifiesta el incumplimiento y al objeto de la prueba, pero no hay distinción en lo que concierne a la carga de la prueba ni a las reglas de atribución de responsabilidad. Y no debe inducir a confusión el que, por la propia naturaleza de la prestación, en las obligaciones de medios, el incumplimiento suponga omisión de la diligencia exigible al deudor. Esa falta de diligencia no es asimilable ni identificable con la culpa regla de imputación de responsabilidad. Como expresa Morales Moreno refiriéndose a esta clase de obligaciones, en ellas "cuando se afirma que el deudor ha incidido en culpa esa afirmación no significa otra cosa que la constatación del hecho objetivo del incumplimiento [...] la culpa expresa en estos casos el incumplimiento del contrato" 24 . En ambas clases de obligaciones son perfectamente distinguibles los ámbitos explicados e iguales las reglas que rigen cada uno de ellos.

\section{BiBLIOGRAFÍA}

- Abeliuk, René (2008). Las obligaciones, tomo I. Santiago: Editorial Jurídica de Chile.

- Badosa Coll, Ferrán (1987). La diligencia y la culpa del deudor en la obligación civil. Bolonia: Publicaciones del Real Colegio de Espańa.

- Baraona GonzÁlez, Jorge (1997). "Responsabilidad contractual y factores de imputación de dańos: apuntes para una relectura en clave objetiva”, Revista Chilena de Derecho, No 24, tomo I.

- Betri, Emilio (1970). Teoría General de las Obligaciones. Madrid: $\mathrm{n} / \mathrm{d}$.

24 Morales Moreno, Antonio Manuel (2009) "Problemas que plantea la unificación del concepto de incumplimiento del contrato", en Derecho de daños. Madrid: Fundación Coloquio Jurídico Europeo, pp. 218 y 219. 
- Brantt Zumarán, María Graciela (2010). El caso fortuito y su incidencia en el derecho de la responsabilidad civil contractual. Concepto y alcance del caso fortuito en el Código Civil chileno. Santiago: Abeledo Perrot.

(2011). "La prueba del cumplimiento imperfecto en las obligaciones de medios y de resultado", en VV.AA: Estudios de Derecho Civil, (en prensa).

- Breccia, Umberto (1968). Diligenza e buona fede nell'attuazione del raporto obligatorio. Milán: Editorial A. Giuffrè.

- Carrasco Perera, Ángel Francisco (1989) "Artículo 1104 Código Civil", en Comentarios al Código Civil y Compilaciones Forales. Madrid: n/d, pp. 8 y ss.

- Del Olmo Guarido, Natalia (2004). El caso fortuito: su incidencia en la ejecución de las obligaciones. Doctrina y jurisprudencia. Navarra: $\mathrm{n} / \mathrm{d}$.

- Díez-Picazo, Luis (2008). Fundamentos del Derecho Civil Patrimonial: Las relaciones obligatorias. Navarra: Editorial Civitas, volumen II, sexta edición.

- Domínguez Águila, Ramón (2008). "La culpa en el derecho civil chileno. Aspectos generales", Revista Anales de Derecho UC. Temas de responsabilidad civil, $\mathrm{n}^{\circ} 3$, pp. 116 y ss.

- Domínguez Hidalgo, Carmen, (2010). "El problema de la culpa presunta contractual y las obligaciones de medios y de resultado: sus implicancias para la responsabilidad médica”, Responsabilidad médica, Cuadernos de Análisis Jurídico, colección derecho privado VI, pp. 24 y ss.

- Faure Abbad, Marianne (2003). Le fait générateur de la responsabilité contractuelle. París: Poitiers.

- Fueyo Laneri, Fernando (2004). Cumplimiento e incumplimiento de las obligaciones, 3ra. edición. Santiago: Editorial Jurídica de Chile.

- García González, Alejandro (2002). Responsabilidad civil contractual. Obligaciones de medios y de resultado. Santiago: Editorial Conosur.

- Jordano Fraga, Francisco (1991). "Obligaciones de medios y de resultado (A propósito de alguna jurisprudencia reciente)", Anuario de Derecho Civil, volumen 44, número 1, pp. 20 y ss.

- Lobato Gómez, J.M. (1992) "Contribución al estudio de la distinción entre las obligaciones de medios y las obligaciones de resultado", Anuario de Derecho Civil, volumen 45, número 2 Peñailillo Arévalo, Daniel (2003). Obligaciones. Teoría General y Clasificaciones. La resolución por incumplimiento. Santiago: Editorial Jurídica de Chile.

- Mengoni, Luigi (1954). "Obbligazione 'di risultato' e obbligazione 'di mezzi”, Rivista dil DirittoCommerciale, no I y II. 
- Morales Moreno, Antonio Manuel (2009). "Problemas que plantea la unificación del concepto de incumplimiento del contrato", en VV.AA: Derecho de daños. Madrid: Fundación Coloquio Jurídico Europeo.

contrato y lucro cesante. Madrid: $\mathrm{n} / \mathrm{d}$.

(2010). Incumplimiento del

- Peńailillo, Daniel (2003). "Responsabilidad contractual objetiva", en VV.AA: Estudios de derecho civil IV. Santiago: Abeledo Perrot.

- Pizarro Wilson, Carlos (2009). "La culpa como elemento constitutivo del incumplimiento", en Revista de Derecho PUCV, XXXI 2.

$-$

(2009a). "Diligencia, incumplimiento y exoneración de responsabilidad. Comentario a sentencia Corte Suprema no ingreso 1.771-2007", en VV.AA: Estudios de Derecho Civil $V$. Santiago: Abeledo Perrot, p. 590 y ss.

- Vidal Olivares, Álvaro (2010). "Incumplimiento y atribución de responsabilidad en las obligaciones de medio y de resultado (a propósito de una sentencia de la Corte Suprema No ingreso 17712008)", en VV.AA: Estudios de Derecho Civil V, Santiago: Abeledo Perrot.

(2010a). "La construcción de la regla contractual en el derecho civil de los contratos", en VV.AA: Incumplimiento contractual, resolución e indemnización de daños. Bogotá: n/d, pp. 33 y ss.

obligaciones con objeto fungible y los remedios del acreedor afectado. Un intento de relectura de las disposiciones del Código Civil sobre incumplimiento”, en VV.AA: El Código Civil de Chile (1885-2005). Trabajos expuestos en el Congreso Internacional celebrado para conmemorar su promulgación. Santiago: Lexis Nexis, p. 514 y ss. 